Article

\title{
Development of a Novel Transparent Flexible Capacitive Micromachined Ultrasonic Transducer
}

\author{
Da-Chen Pang * and Cheng-Min Chang \\ Department of Mechanical Engineering, National Kaohsiung University of Applied Sciences, \\ 415 Jian Gong Rd., Sanmin Dist., Kaohsiung 80778, Taiwan; v6302001@gmail.com \\ * Correspondence: pang@kuas.edu.tw; Tel.: +886-909-129-294
}

Received: 27 April 2017; Accepted: 15 June 2017; Published: 20 June 2017

\begin{abstract}
This paper presents the world's first transparent flexible capacitive micromachined ultrasonic transducer (CMUT) that was fabricated through a roll-lamination technique. This polymer-based CMUT has advantages of transparency, flexibility, and non-contacting detection which provide unique functions in display panel applications. Comprising an indium tin oxide-polyethylene terephthalate (ITO-PET) substrate, SU-8 sidewall and vibrating membranes, and silver nanowire transparent electrode, the transducer has visible-light transmittance exceeding $80 \%$ and can operate on curved surfaces with a $40 \mathrm{~mm}$ radius of curvature. Unlike the traditional silicon-based high temperature process, the CMUT can be fabricated on a flexible substrate at a temperature below $100{ }^{\circ} \mathrm{C}$ to reduce residual stress introduced at high temperature. The CMUT on the curved surfaces can detect a flat target and finger at distances up to $50 \mathrm{~mm}$ and $40 \mathrm{~mm}$, respectively. The transparent flexible CMUT provides a better human-machine interface than existing touch panels because it can be integrated with a display panel for non-contacting control in a health conscious environment and the flexible feature is critical for curved display and wearable electronics.
\end{abstract}

Keywords: capacitive micromachined ultrasonic transducer; flexible transducer; silver nanowire transparent electrode; SU-8; human-machine interface

\section{Introduction}

In 1989, Hohm and Hess [1] presented the first capacitive ultrasonic transducer. The earlier transducers were fabricated using anisotropic etching of silicon backplates [1-3]. In 1994, Haller and Khuri-Yakub [4] developed a capacitive micromachined ultrasonic transducer (CMUT) using sacrificial-layer technology. The Khuri-Yakub group at Stanford University had also proposed fabrication improvements and CMUT applications in the literature [5-9]. In 2003, Huang et al. [10] fabricated a CMUT using wafer bonding technology to ensure fewer process steps and better product quality compared with the sacrificial-layer processes. The wafer bonding technology including anodic bonding, fusion bonding, and adhesive bonding has been extensively applied in the fabrication of CMUTs [11-18]. The opaqueness of silicon wafers to visible light causes non-transparent properties in silicon-based CMUTs. Since infrared light can pass through silicon, Chen et al. [19] presented an infrared-transparent CMUT for photoacoustic imaging in 2012.

In 2006, Chang et al. [20] pioneered a polymer-based CMUT using sacrificial-layer techniques and later fabricated on a polymer substrate so the CMUT was flexible [21]. The CMUTs on an ultrathin silicon wafer also feature bending characteristics [22]. In 2008, Zhuang et al. [23] etched trenches into silicon wafers and filled them with polydimethylsiloxane (PDMS) to fabricate flexible CMUT arrays. In 2008, Abgrall et al. [24] applied the lamination technique for minimizing residual stress to fabricate SU-8 bonding structures at low pressure and temperature. In 2012, Shi et al. [25] used Polydimethylsiloxane (PDMS) and bonding technology to fabricate a stretchable CMUT but the CMUT 
was not transparent due to the metal electrodes. In 2015, Li et al. [26] fabricated a polymer-based CMUT using photo benzocyclobutene and bonding technology but the membrane was made of silicon nitride and the process temperature was up to $250^{\circ} \mathrm{C}$. In 2015, Bui et al. [27] used a polymer-based CMUT to measure surface roughness. All the polymer-based CMUTs above were non-transparent.

The purpose of this research is to develop a novel fabrication process for a transparent flexible CMUT so the CMUT can be applied in a display panel for finger hovering that provides a more advanced human-machine interface than the existing touch panel. A new roll-lamination fabrication technique is proposed for the mass production of CMUTs at low temperature. The roll-lamination method minimizes the residual stress introduced at high temperature if a bonding process is used. This fabrication method is also simpler than the sacrificial-layer technique. Three different transparent electrodes, indium tin oxide (ITO), aluminum-doped zinc oxide (AZO), and silver nanowire, are fabricated and tested in our CMUTs. The transparent electrodes on the vibrating membranes must survive ultrasonic vibration under long term operation. The performance characteristics of the transparent flexible CMUT are tested on flat and curved surfaces. The proposed CMUT can be easily integrated with display panels and lighting systems for non-contacting sensing and control in the future. Figure 1 shows the research progress of our group over the years.

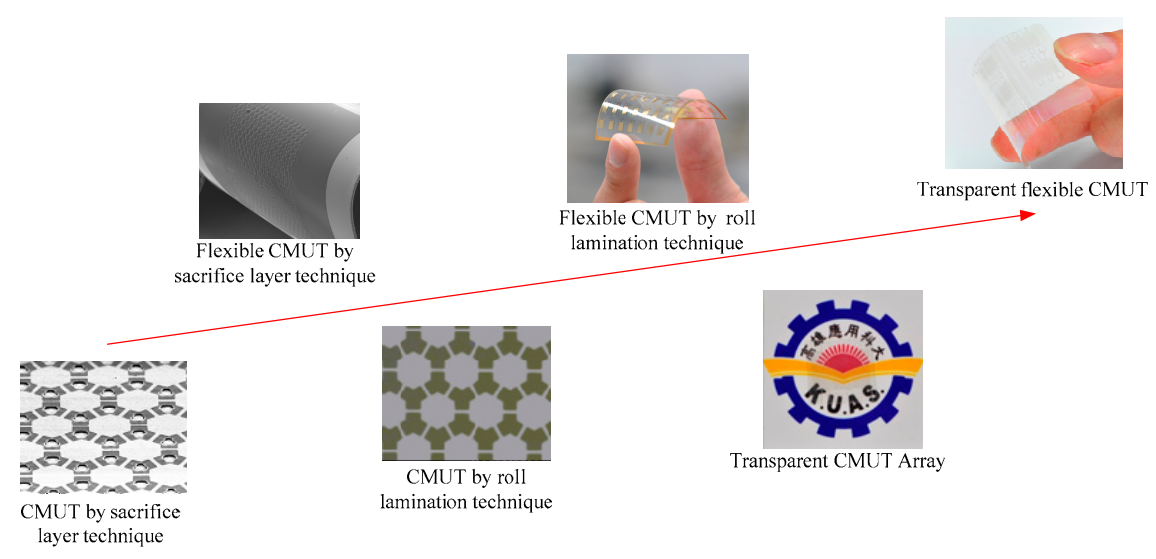

Figure 1. CMUT research results from our group.

\section{CMUT Design}

The proposed transparent CMUT has a surface area of $3 \mathrm{~mm} \times 3 \mathrm{~mm}$ and comprises 416 hexagoninscribed vibrating membranes with a diameter of $140 \mu \mathrm{m}$, as illustrated in Figure 2. The ITO-PET substrate was $125 \mu \mathrm{m}$ in thickness, the sidewall was $10 \mu \mathrm{m}$ in width, the cavity was $2 \mu \mathrm{m}$ in depth, and the vibrating membranes, which sandwiched a $0.2 \mu \mathrm{m}$ thick silver nanowire (SNW) transparent electrode, were $5 \mu \mathrm{m}$ in thickness as shown in Figure 3. The design dimensions are listed in Table 1. A total of 72 CMUTs with an overall size of $8 \mathrm{~cm} \times 6 \mathrm{~cm}$ were fabricated on a 4-inch silicon wafer.

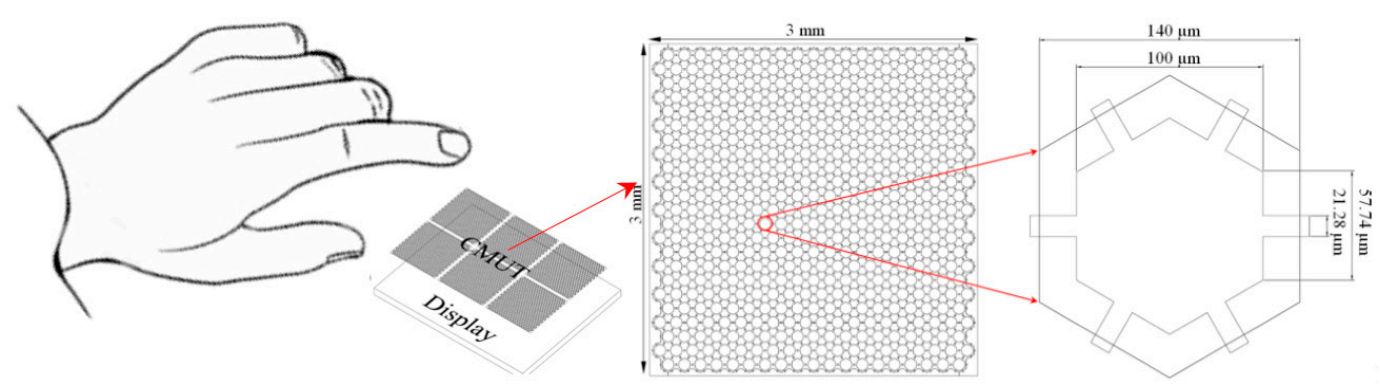

Figure 2. Schematic Diagram of finger hovering using a transparent capacitive micromachined ultrasonic transducer (CMUT). 


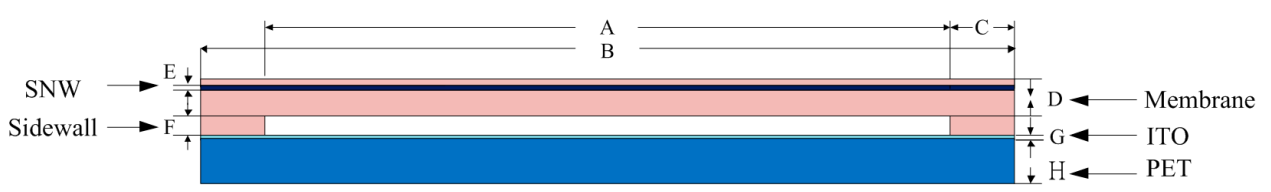

Figure 3. Cross-sectional view of a transparent CMUT.

Table 1. Transparent CMUT dimensions.

\begin{tabular}{lcc|lcc}
\hline Membrane diameter & A & $140 \mu \mathrm{m}$ & Membrane thickness & D & $5 \mu \mathrm{m}$ \\
\hline $\begin{array}{l}\text { Silver nanowire (SNW) } \\
\text { electrode diameter }\end{array}$ & B & $160 \mu \mathrm{m}$ & SNW electrode thickness & E & $0.2 \mu \mathrm{m}$ \\
\hline Sidewall height & $\mathrm{F}$ & $2 \mu \mathrm{m}$ & Sidewall width & $\mathrm{C}$ & $10 \mu \mathrm{m}$ \\
\hline $\begin{array}{l}\text { Indium Tin Oxide (ITO) } \\
\text { electrode thickness }\end{array}$ & $\mathrm{G}$ & $0.2 \mu \mathrm{m}$ & $\begin{array}{l}\text { Polyethylene terephthalate } \\
\text { (PET) thickness }\end{array}$ & $\mathrm{H}$ & $125 \mu \mathrm{m}$ \\
\hline
\end{tabular}

\section{Fabrication}

The fabrication of the transparent flexible CMUT was built on a polymer-based CMUT using sacrificial-layer techniques developed earlier. The polymer-based CMUT applied a PET substrate and SU-8 structure and membrane. It was not transparent because platinum and gold were used for the electrodes. The sacrificial-layer fabrication procedure of the polymer-based CMUT, depicted in Figure 4, is described as follows:

1. Paste a PET flexible substrate onto a silicon wafer and sputter a $0.3 \mu \mathrm{m}$ thick platinum electrode.

2. Pattern a $2 \mu \mathrm{m}$ thick AZ4620 photoresist to protect the sidewall area, followed by soft baking at $95^{\circ} \mathrm{C}$ for $2 \mathrm{~min}$.

3. Electroform $2 \mu \mathrm{m}$ thick copper as a sacrificial layer. Remove the AZ4620 photoresist.

4. Pattern a SU-8 2002 photoresist to form a sidewall and vibrating membrane. Perform a soft bake at $65{ }^{\circ} \mathrm{C}$ for $4 \mathrm{~min}$ and $95^{\circ} \mathrm{C}$ for $4 \mathrm{~min}$, and then post exposure bake at $65^{\circ} \mathrm{C}$ for $2 \mathrm{~min}$ and $95{ }^{\circ} \mathrm{C}$ for $3 \mathrm{~min}$.

5. Develop the SU-8 2002 photoresist to yield etching holes. Perform a hard bake at $95{ }^{\circ} \mathrm{C}$ for $5 \mathrm{~min}$.

6. Deposit $0.3 \mu \mathrm{m}$ thick gold to yield the top electrode layer.

7. Pattern-etch the top electrode using the AZ4620 photoresist and potassium iodine.

8. Remove the copper sacrificial layer to release the vibrating membranes and cavities.

9. Remove the silicon wafer to complete the CMUT fabrication.

This research developed a new roll-lamination fabrication procedure for the transparent flexible CMUT without time and cost for the electroforming process compared with the sacrificial-layer technique. The CMUT exhibited transparency and flexibility by employing an ITO-PET substrate, SU 8 structure and membrane, and silver nanowire electrode. The new fabrication method applied the roll-lamination technique and dip coating process so the process temperatures were below $100{ }^{\circ} \mathrm{C}$. The fabrication procedure of the transparent flexible CMUT, illustrated in Figure 5, is described as follows:

1. Paste a $125 \mu \mathrm{m}$ thick ITO-PET substrate onto a silicon wafer.

2. Spin coat a $2 \mu \mathrm{m}$ thick SU-8 2002 photoresist onto the ITO-PET substrate, followed by soft bake at $65{ }^{\circ} \mathrm{C}$ for $3 \mathrm{~min}, 95^{\circ} \mathrm{C}$ for $3 \mathrm{~min}$, and then $65^{\circ} \mathrm{C}$ for $3 \mathrm{~min}$.

3. Pattern the SU-8 2002 photoresist to form a sidewall. Perform a post exposure bake at $65^{\circ} \mathrm{C}$ for $3 \mathrm{~min}, 95^{\circ} \mathrm{C}$ for $3 \mathrm{~min}$, and $65^{\circ} \mathrm{C}$ for $3 \mathrm{~min}$, and then hard bake at $65^{\circ} \mathrm{C}$ for $2 \mathrm{~min}, 95{ }^{\circ} \mathrm{C}$ for $4 \mathrm{~min}$, and $65^{\circ} \mathrm{C}$ for $2 \mathrm{~min}$.

4. Prepare a $4 \mu \mathrm{m}$ thick SU-8 2002 photoresist on a PET release layer, followed by soft bake at $65^{\circ} \mathrm{C}$ for $3 \mathrm{~min}$ and then $95^{\circ} \mathrm{C}$ for $2 \mathrm{~min}$. 
5. Roll-laminate the PET release layer containing the SU-8 2002 photoresist as vibrating membranes onto the sidewall at an average pressure of $0.35 \mathrm{MPa}$.

6. Expose the SU-8 2002 photoresist on the PET release layer, followed by post exposure bake at $65^{\circ} \mathrm{C}$ for $1 \mathrm{~min}, 95^{\circ} \mathrm{C}$ for $1 \mathrm{~min}$, and $65^{\circ} \mathrm{C}$ for $1 \mathrm{~min}$. Remove the PET release layer and develop the vibrating membranes.

7. Prepare a $0.2 \mu \mathrm{m}$ thick transparent silver nanowire electrode through dip coating.

8. Spin coat a $1 \mu \mathrm{m}$ thick SU-8 2002 photoresist onto the vibrating membranes, followed by soft bake at $65{ }^{\circ} \mathrm{C}$ for $2 \mathrm{~min}, 95^{\circ} \mathrm{C}$ for $2 \mathrm{~min}$, and then $65^{\circ} \mathrm{C}$ for $2 \mathrm{~min}$. Pattern the SU-8 2002 photoresist to form a protect layer. Perform a post exposure bake at $65^{\circ} \mathrm{C}$ for $2 \mathrm{~min}, 95^{\circ} \mathrm{C}$ for $2 \mathrm{~min}$, and $65^{\circ} \mathrm{C}$ for $2 \mathrm{~min}$, and hard bake at $65^{\circ} \mathrm{C}$ for $2 \mathrm{~min}, 95^{\circ} \mathrm{C}$ for $3 \mathrm{~min}$, and $65^{\circ} \mathrm{C}$ for $2 \mathrm{~min}$.

9. Remove the silicon wafer to complete the transparent CMUT fabrication.

The minimum membrane thicknesses for sacrificial-layer and roll-lamination fabrication procedures are $1 \mu \mathrm{m}$ and $2 \mu \mathrm{m}$, respectively. The limitation of membrane thickness in the roll-lamination fabrication procedure is due to the removal of the PET release layer in step 6. Considering the ratio of membrane thickness over diameter, the sacrificial-layer fabrication procedure achieves the state-of-the-art in micromachining polymer-based CMUTs.

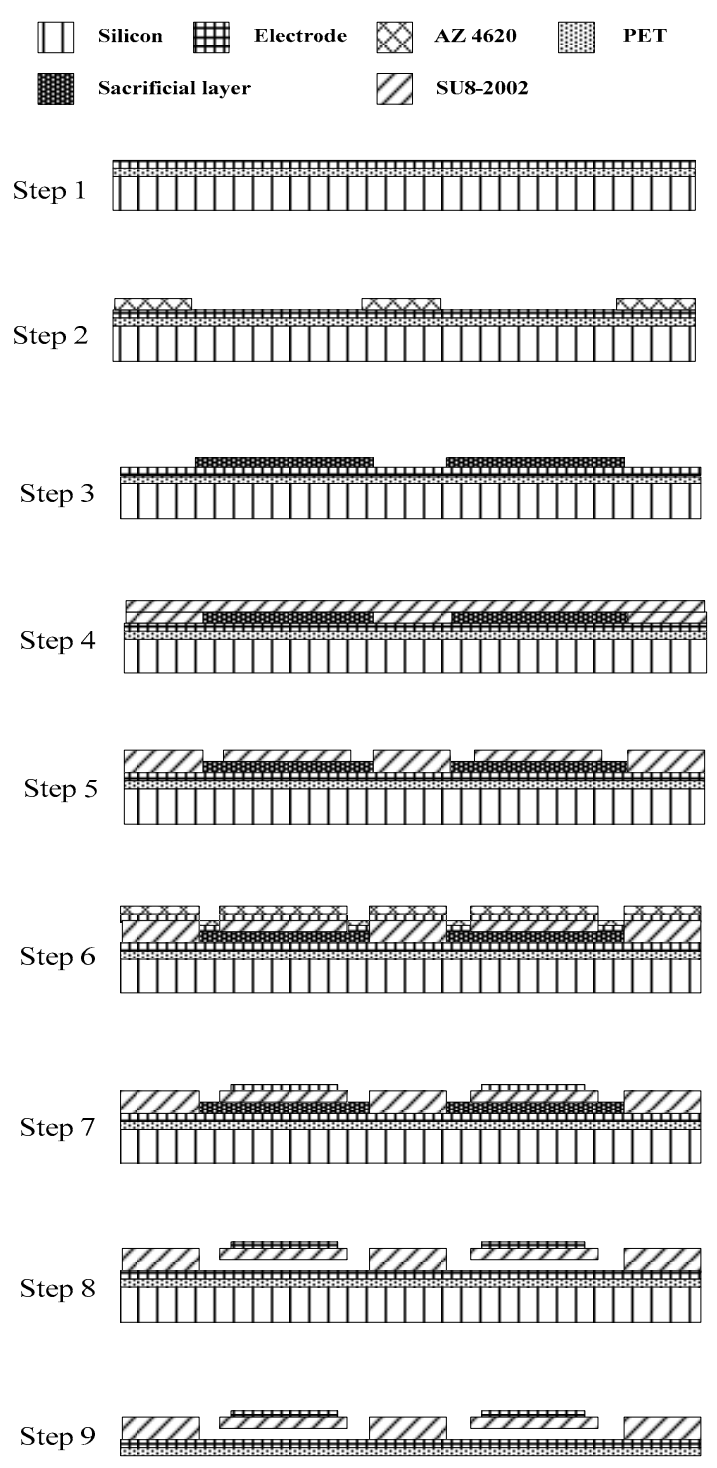

Figure 4. CMUT made by the sacrificial-layer fabrication technique. 


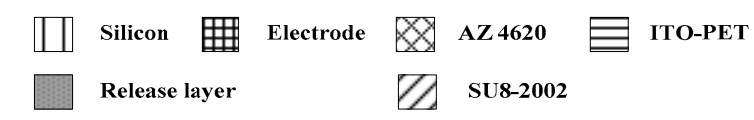

Step 1

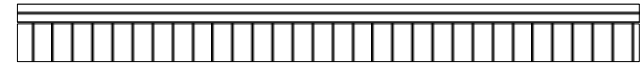

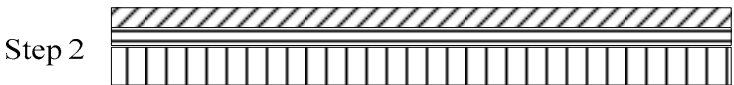

Step 3

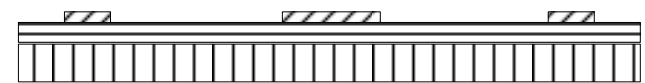

Step 4

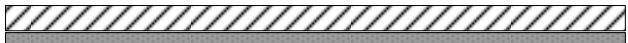

Step 5

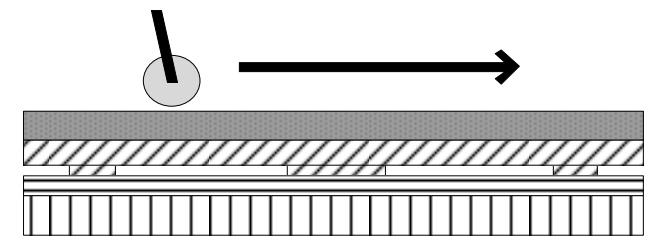

Step 6

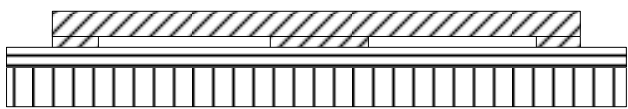

Step 7

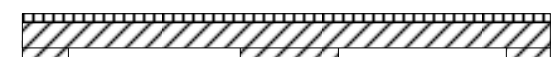

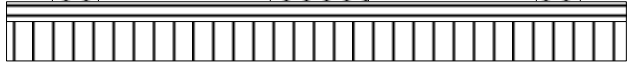

Step 8

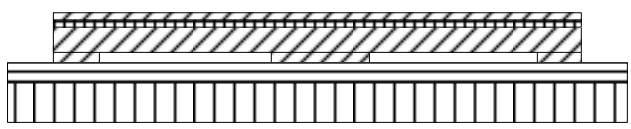

Step 9

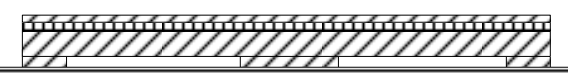

Figure 5. Transparent CMUT made by the roll-lamination fabrication technique.

Figure 6a,b illustrate two CMUTs made respectively by the sacrificial-layer and roll-lamination techniques. Both figures show top electrodes made of gold because the electrode patterns are not clear with silver nanowire. The left and right images were obtained using an optical microscope (OM) and scanning electron microscope (SEM). The etching holes from the sacrificial-layer technique are clearly shown in Figure 6a, whereas there was no hole seen through the roll-lamination technique in Figure 6b.

A transparent flexible CMUT was successfully fabricated using the proposed roll-lamination techniques. Figure 7 presents non-transparent (left image) and transparent (right image) CMUTs with gold and silver nanowire top electrodes. Figure 8 shows a transparent CMUT under deflection. The performance characteristics of these two CMUTs were tested and compared. 


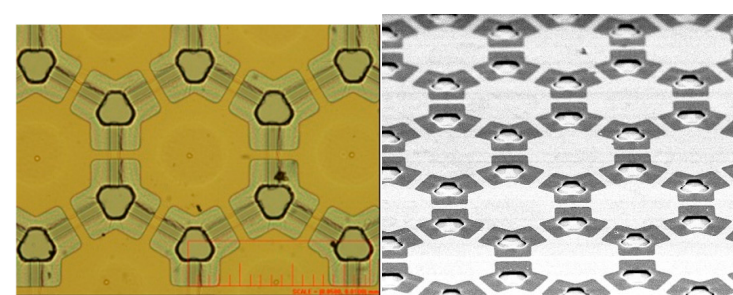

(a)

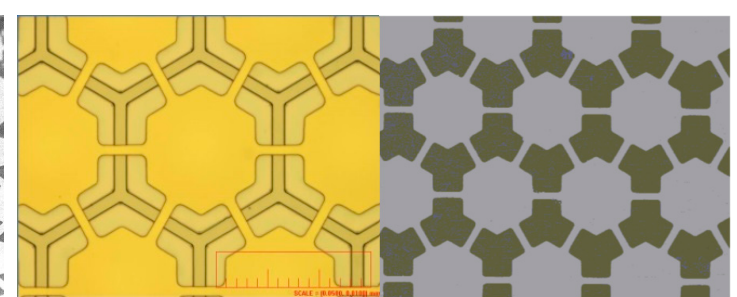

(b)

Figure 6. (a) CMUT made by the sacrificial-layer technique (left: optical microscope (OM) image; right: scanning electron microscope (SEM) image); (b) CMUT made by the roll-lamination technique (left: OM image; right: SEM image).
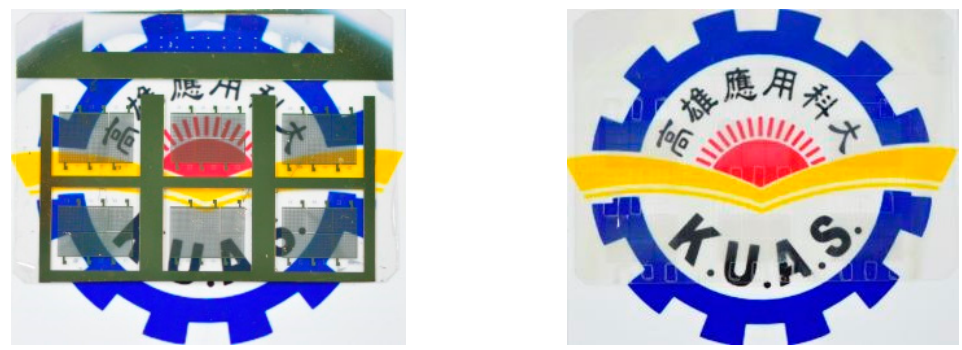

Figure 7. CMUTs with gold (left) and silver nanowire (right) top electrodes.

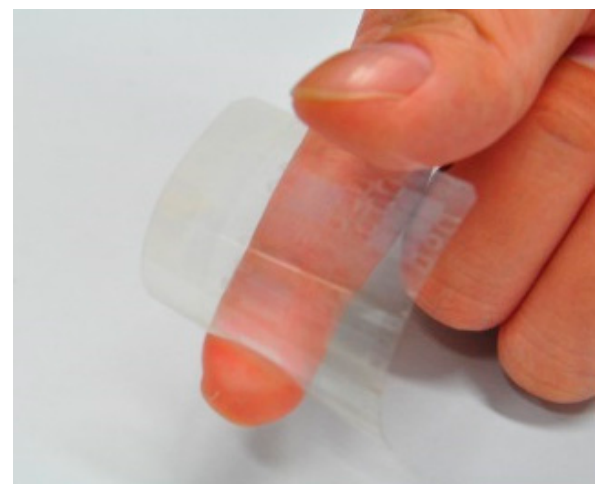

Figure 8. A transparent flexible CMUT.

\section{Discussion}

\subsection{Roll-Lamination Fabrication}

Fabricating a flexible CMUT through roll-lamination techniques involves two critical steps: (1) preparing vibrating membranes on a PET release layer, and (2) laminating the membranes onto the sidewall. The SU-8 vibrating membranes should be prepared on a PET release layer with a baking temperature below $100^{\circ} \mathrm{C}$. If the temperature is higher than $120^{\circ} \mathrm{C}$, membrane deformation occurs on the PET release layer. The membrane preparation in step (4) with baking times increasing more than $10 \mathrm{~s}$ result in an excessively dry SU-8 photoresist, which causes the membranes to fail to laminate onto the sidewall; this is evident when many bubbles form at the junction between the sidewall and the membrane during lamination. The baking times decreasing more than $10 \mathrm{~s}$ lead to an overly wet photoresist, which causes the membranes to detach from the sidewall when the release layer is removed; this is evident when the cavity is exposed or when there are holes on the membranes.

Successful lamination of vibrating membranes onto the sidewall depends largely on the lamination pressure. When the lamination pressure is below $0.3 \mathrm{MPa}$, the membranes and sidewall fail to bond; 
when the lamination pressure is over $0.6 \mathrm{MPa}$, the sidewall becomes deformed. A Fuji Prescale film is used to measure the lamination pressure and its uniformity on the membranes; this is achieved by placing the film on the PET release layer, observing the color change on the release layer following lamination (yellow: $>0.6 \mathrm{MPa}$; red: $0.3-0.6 \mathrm{MPa}$; green: $<0.3 \mathrm{MPa}$ ), and measuring the levels of lamination pressure on the four regions (upper, lower, left, and right) of the release layer. Figure 9 illustrates the lamination pressure distribution on four Prescale films tested by applying various pressure levels. In Sample 1, the lamination pressure has an average of $0.35 \mathrm{MPa}$ and is more uniform on the left half than on the right half; the membranes on the right half region indicated by the green color could not be laminated onto the sidewall. In Sample 2, the lamination pressure was uniform with an average of $0.39 \mathrm{MPa}$ across all the regions; thus, this sample represented the highest success rate among the four samples. In Sample 3, the lamination pressure has an average of 0.4 MPa and the central region has better lamination compared with the surrounding regions. In Sample 4, the lamination pressure was not uniform with an average less than $0.31 \mathrm{MPa}$; thus, this sample represented the lowest success rate. Note that the best lamination pressure is between 0.35 and $0.55 \mathrm{MPa}$.

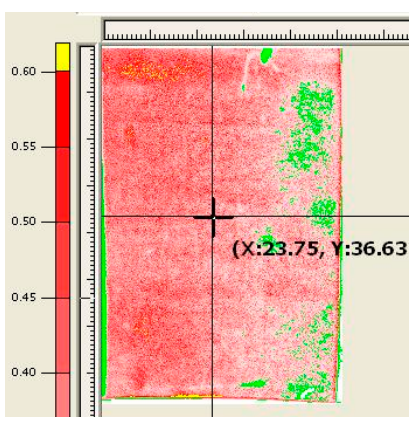

Sample 1

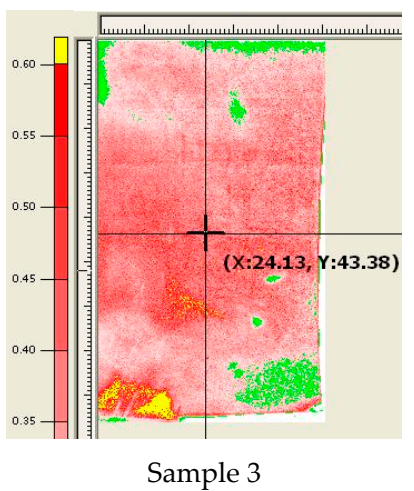

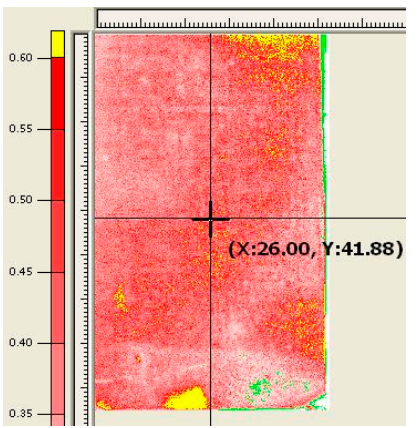

Sample 2

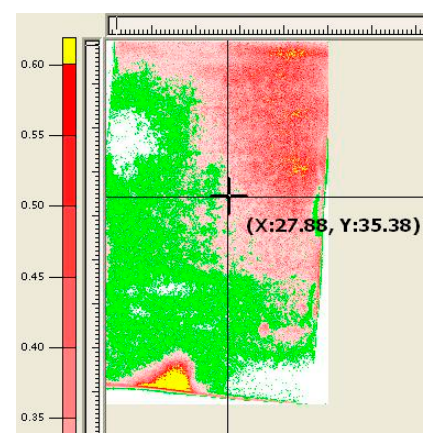

Sample 4

Figure 9. Lamination pressure distribution on four Prescale films. The red color indicates good bonding pressure; the green color with lower pressure leads to bonding failure; the yellow color with higher pressure causes the sidewall deformed. Sample 1 has good lamination on the left half region but not right half region; sample 2 with an uniform and correct pressure is the best among four samples; sample 3 applied uneven pressure leads to good lamination in the central region but not surrounding regions; sample 4 with lower than ideal pressure is the worst.

\subsection{Transparent Electrodes}

Three transparent electrode materials, ITO, AZO, and silver nanowire, were used to prepare the CMUT top electrodes to replace the gold top electrode. The ITO top electrode was prepared through vacuum deposition at a vacuum level of $10^{-5}$ Torr and with a deposition rate of $0.8 \AA / \mathrm{s}$, deposition thickness of approximately $200 \mathrm{~nm}$, and sheet resistance of 160-200 $\Omega$ /sq using a four-point probe. The AZO top electrode was prepared through magnetron sputtering at a vacuum level of $10^{-3}$ Torr and with a deposition rate of $0.5 \AA$ /s, deposition thickness of approximately $200 \mathrm{~nm}$, and 
sheet resistance of 230-270 $\Omega$ /sq. The conductivities of the ITO and AZO electrode cannot meet the conductivity of the gold electrode but reach the normal quality of a transparent conducting film. The silver nanowire electrodes were fabricated by Material and Chemical Laboratories of the Industrial Technology Research Institute, Hsinchu, Taiwan.

The SU-8 membrane surface should be modified before coating a silver nanowire electrode. The hydrophobicity of the SU-8 membranes causes unevenly distributed silver nanowire paste, so the electrodes have low transmittance and conductivity. The SU- 8 membranes were subject to a corona discharge treatment and the contact angle between the SU-8 and silver nanowire paste was dropped from $66^{\circ}$ to $22^{\circ}$. The silver nanowire electrodes were prepared through three different fabrication methods: spin coating, spray coating, and dip coating. The silver paste has a nanowire length of 5-25 $\mu \mathrm{m}$ and nanowire diameter of $25-45 \mathrm{~nm}$. The $200 \mathrm{~nm}$ thick silver nanowire electrode has a sheet resistance up to the $60 \Omega$ /sq similar to the gold electrode. To achieve the same sheet resistance the dip coating was processed once, spin coating twice, and spray coating four times. The transparency of the electrode drops quickly with more processes so dip coating with the highest transmittance is the best choice. Figure 10a shows a poorly distributed silver nanowire electrode coated on untreated SU-8 membranes. Figure 10b displays a well-distributed and transparent silver nanowire electrode coated on treated SU-8 membranes.

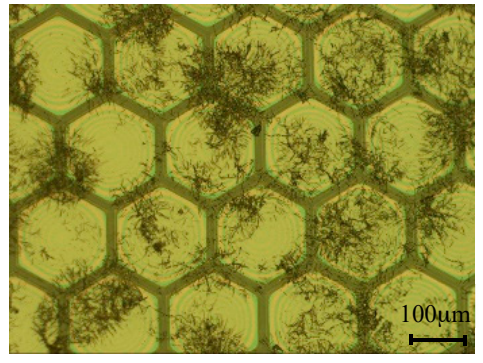

(a)

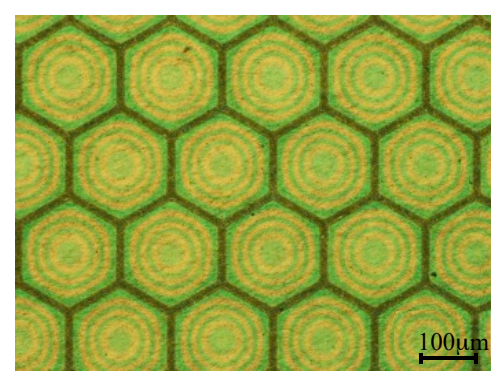

(b)

Figure 10. (a) Poorly distributed silver nanowire electrode coated on untreated SU-8 membranes;

(b) Well-distributed and transparent silver nanowire electrode coated on treated SU-8 membranes.

The transmittance of four CMUTs with gold, ITO, AZO, and silver nanowire top electrodes was measured using a Shimadzu UV-1800 spectrometer (Shimadzu Corporation, Kyoto, Japan) in the visible wavelength range, $380-780 \mathrm{~nm}$. The transmittance levels of the gold, ITO, AZO, and silver nanowire top electrodes were $39.7 \%, 83.2 \%, 84.1 \%$, and $84.2 \%$, respectively. The CMUTs with ITO, AZO, and silver nanowire electrodes all exceed the $80 \%$ transmittance threshold for transparent conducting films. Figure 11 shows the transmittance measurements of the CMUTs with different top electrodes.

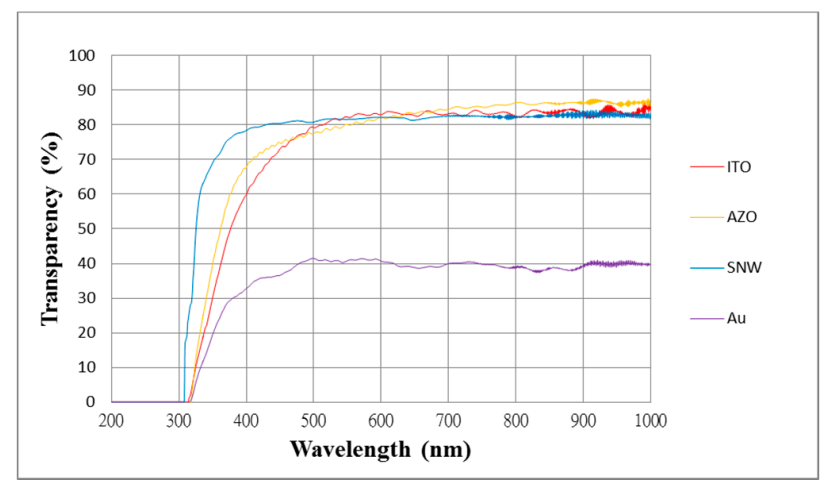

Figure 11. Transmittance measurements of CMUTs with gold, ITO, aluminum-doped zinc oxide (AZO), and silver nanowire top electrodes. 
The CMUTs with transparent top electrodes were tested by performing pulse-echo experiments under AC $300 \mathrm{~V}$ and DC $100 \mathrm{~V}$ bias voltage conditions. The CMUTs with ITO and AZO top electrodes malfunctioned after transmitting ultrasonic signals for less than five minutes. Observation through an optical microscope revealed cracks on the electrodes, which were caused by the vibrating membrane. The cracks of the ITO and AZO top electrodes are clearly shown in Figure 12a,b. There was no improvement with the coating protecting layer. No prior study has investigated the behaviors of ITO and AZO top electrodes under ultrasonic vibration operations, although several studies have reported the increased resistivity of electrodes caused by cyclic bending [28-34]. However, the resistivity of the silver nanowire electrode reported no change in sheet resistance when flexed over 1000 cycles [35]; thus, the silver nanowire was further investigated as the top electrode for the proposed CMUT.

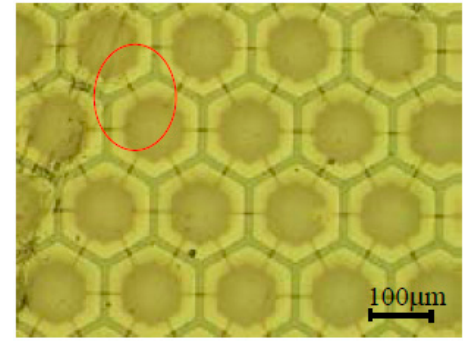

(a)

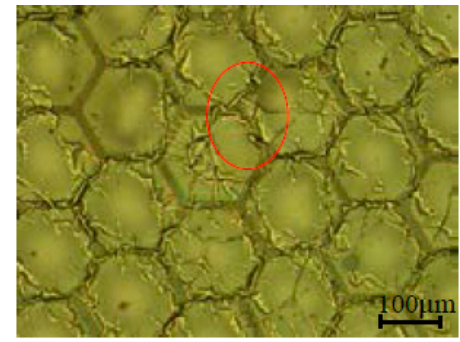

(b)

Figure 12. (a) Cracks on the ITO top electrode after the pulse-echo test; (b) Cracks on the AZO top electrode after the pulse-echo test.

The silver nanowire electrode should be coated with an appropriate protecting layer to prevent the vibration of the membrane from peeling off silver nanowires. The CMUTs with silver nanowire top electrodes were also tested by performing pulse-echo experiments under AC $300 \mathrm{~V}$ and DC $100 \mathrm{~V}$ bias voltage conditions for a period from 4 to $24 \mathrm{~h}$ more than twenty times. When the electrode was first coated with a $200 \mathrm{~nm}$ thick protecting layer, warpages occurred on the protecting layer and silver nanowires were peeled off after a pulse-echo experiment for $4 \mathrm{~h}$ as shown in Figure 13a. The warpages caused an open circuit of the CMUT. In this study, a $200 \mathrm{~nm}$ thick silver nanowire transparent electrode was fabricated on a $4 \mu \mathrm{m}$ thick SU- 8 membrane and was subsequently coated with a $1 \mu \mathrm{m}$ thick SU-8 protecting layer. There is no warpage of the protecting layer or peeling of the silver nanowire after the pulse-echo test for $24 \mathrm{~h}$ as shown in Figure 13b.

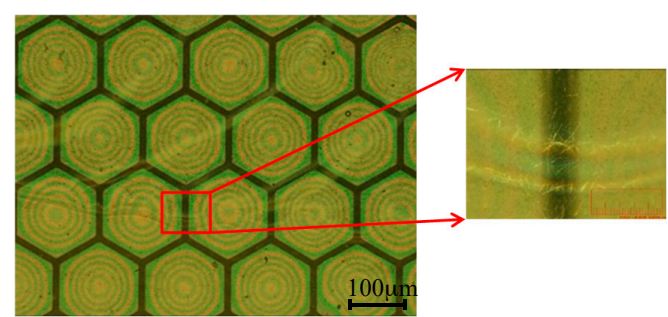

(a)

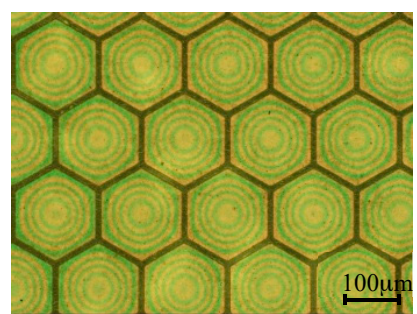

(b)

Figure 13. (a) Surface warpage observed on a protecting layer after the pulse-echo test; (b) No warpage observed on a $1 \mu \mathrm{m}$ SU-8 protecting layer after the pulse-echo test.

Table 2 summaries the performances of the CMUTs with gold, ITO, AZO, and silver nanowire top electrodes. The CMUTs with ITO and AZO top electrodes can be bent or flexed but were damaged after the pulse-echo test for less than five minutes. Thus, both electrodes cannot be used in ultrasound applications. However, the silver nanowire electrode with the SU-8 protecting layer is the best choice for the transparent flexible CMUTs. 
Table 2. Performances of CMUTs with gold, ITO, AZO, and silver nanowire top electrodes.

\begin{tabular}{ccccc}
\hline & Gold & ITO & AZO & SNW \\
\hline Thickness $(\mathrm{nm})$ & $\sim 150$ & $\sim 200$ & $\sim 200$ & $\sim 200$ \\
Sheet resistance $(\Omega / \mathrm{sq})$ & $10-60$ & $160-200$ & $230-270$ & $10-60$ \\
Transmittance $(\%)$ & 39.4 & 83.2 & 84.1 & 84.2 \\
Color & Gold & Transparent & Transparent & Transparent \\
Flexibility & Good & OK & OK & Good \\
Ultrasound Application & Good & Damaged & Damaged & Good \\
\hline
\end{tabular}

\subsection{Membrane Swelling}

The SU-8 vibrating membranes of the CMUTs swelled initially after fabrication and further expanded after extended use. The swelling behavior is influenced by the baking procedure in photoresist development process and internal stresses in the SU-8 film [36]. The swelling height was obtained by calculating the number of Newton's rings on the membrane and by using a Keyence VK-X250 3D laser microscope. There were six Newton's rings observed on the transparent CMUT membranes after fabrication, and this increased to 14 rings after over $24 \mathrm{~h}$ of continuous operation, as shown in Figure 14. In addition, the 3D microscope revealed that the swelling height increased from 0.9 to $2.0 \mu \mathrm{m}$, as shown in Figure 15. The membrane swelling enlarged the distance between the top and bottom electrodes and caused a reduction in ultrasonic signals of the CMUT.

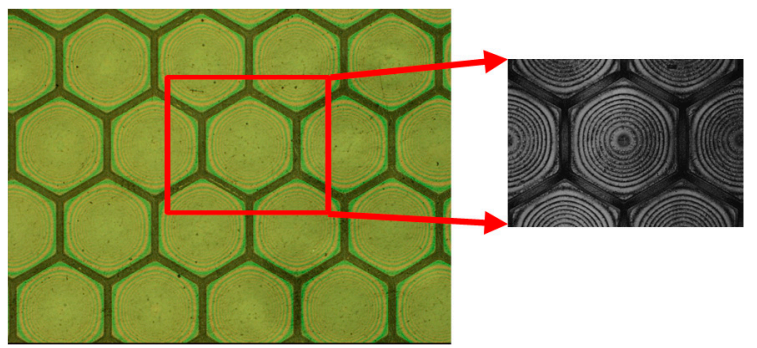

Figure 14. Newton's rings on the membranes increase in number after $24 \mathrm{~h}$ of operation.
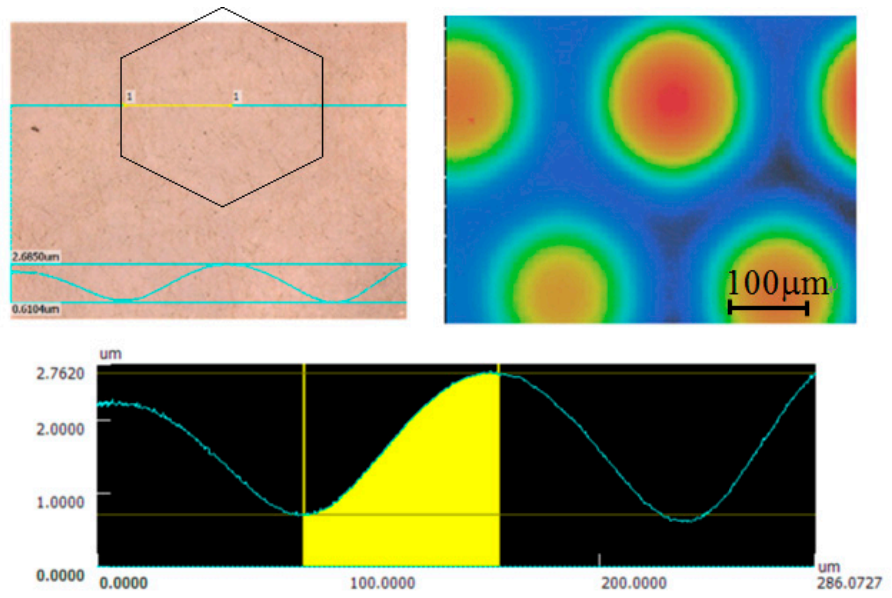

Figure 15. Swelling of the transparent CMUT membranes after $24 \mathrm{~h}$ of operation.

\section{CMUT Characteristics Measurement}

The performance of the transparent CMUT with the silver nanowire top electrode was investigated using pulse-echo tests and compared to the CMUT with the gold top electrode. Figure 16 illustrates the framework of the CMUT pulse-echo experiment. The tests included operating voltage conditions, 
time and frequency responses under a $24 \mathrm{~h}$ operation, detection distance versus time of flight, and maximum detection distances with CMUTs mounted on flat and curved surfaces.

The operating voltage conditions were tested on the transparent CMUT by detecting a flat target at a distance of $10 \mathrm{~mm}$ at various AC pulse voltages and DC bias voltages. The AC pulse voltage was increased from 150 to $300 \mathrm{~V}$ in $50 \mathrm{~V}$ increments, whereas the DC bias voltage was increased from 75 to $150 \mathrm{~V}$ in $25 \mathrm{~V}$ increments. The upper limits of both the AC and DC voltages were specified to prevent transducer burnout. Figure 17 shows the spectra of the received signals of the transparent CMUT at different operating voltage conditions. The CMUT can detect the maximum distance at the AC $300 \mathrm{~V}, \mathrm{DC} 100 \mathrm{~V}$ condition and had a resonance frequency of $880 \mathrm{kHz}$ with a maximum amplitude of $-18.6 \mathrm{~dB}$.

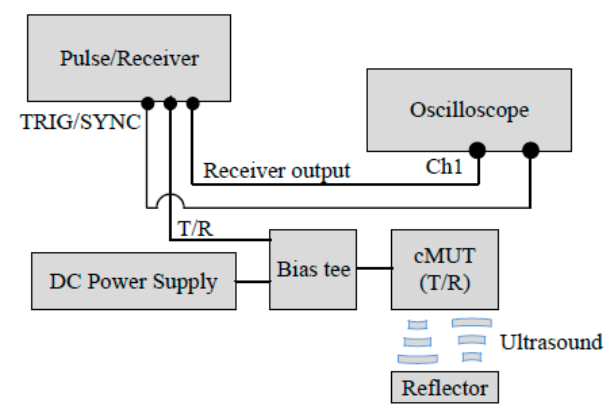

Figure 16. CMUT pulse-echo test framework.

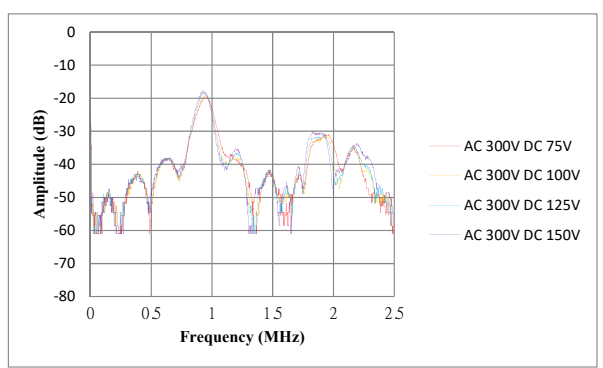

(a)

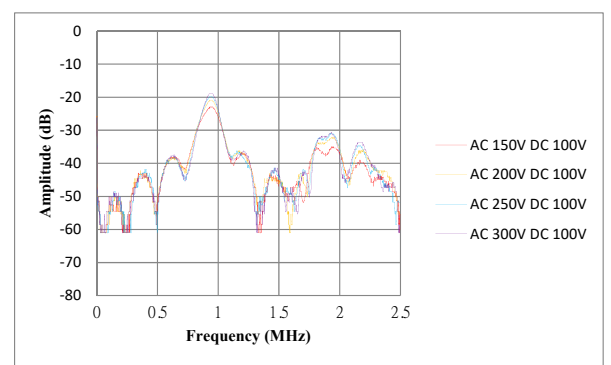

(b)

Figure 17. (a) Spectra of received signals of the transparent CMUT under AC $300 \mathrm{~V}$ and various DC bias voltage; (b) Spectra of received signals of the transparent CMUT under DC $100 \mathrm{~V}$ and various AC pulse voltage.

Figure 18a,b present the time and frequency responses of both gold and silver nanowire CMUTs operating for $24 \mathrm{~h}$ at the AC $300 \mathrm{~V}, \mathrm{DC} 100 \mathrm{~V}$ condition by detecting a flat target at a distance of $10 \mathrm{~mm}$. The maximum amplitudes of the first reflection signal for the gold and silver nanowire CMUT were 860 and $960 \mathrm{mV}$, respectively. The natural frequencies were $880 \mathrm{kHz}$ for both CMUTs. There is no change was observed during $24 \mathrm{~h}$ of operation.

Figure 19 shows the detection distance versus time of flight experiments for both gold and silver nanowire CMUTs. The experiments were conducted at room temperature $25{ }^{\circ} \mathrm{C}$ with the target distances ranging from 5 to $70 \mathrm{~mm}$ in $5 \mathrm{~mm}$ increments. Each measurement was repeated three times. The propagation speeds for the gold and silver nanowire CMUTs were $347.5 \mathrm{~m} / \mathrm{s}$ and $346.5 \mathrm{~m} / \mathrm{s}$, respectively. The linearity errors of the displacement were $0.136 \mathrm{~mm}$ and $0.141 \mathrm{~mm}$.

Figure 20 illustrates detection distance versus reflection signal experiments for both gold and silver nanowire CMUTs. The maximum detection distances were $70 \mathrm{~mm}$ for both CMUTs. The maximum reflection signals for gold and silver nanowire CMUTs were $864 \mathrm{mV}$ and $888 \mathrm{mV}$ at a $10 \mathrm{~mm}$ detection distance, and decreased to $84 \mathrm{mV}$ and $66 \mathrm{mV}$ at $70 \mathrm{~mm}$. There were only slight differences observed for both CMUTs. 

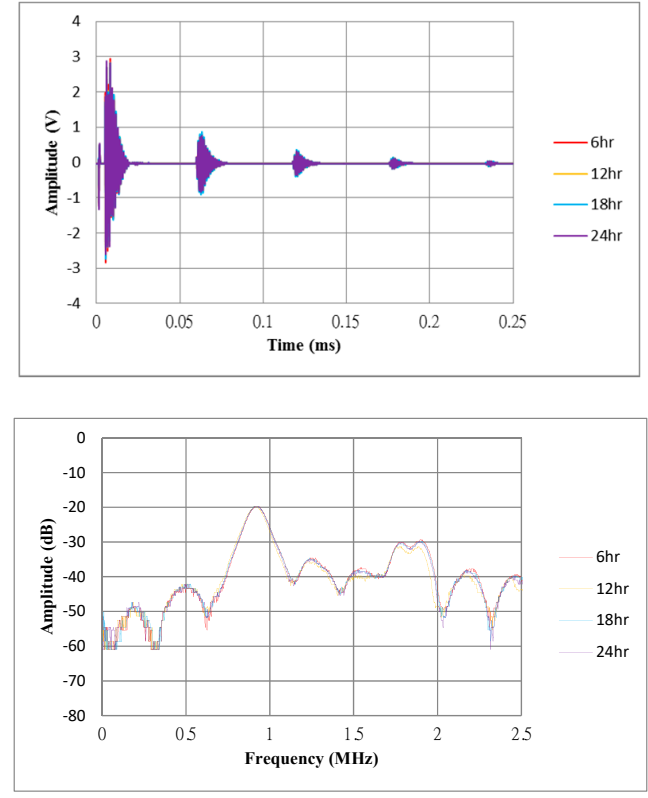

(a)
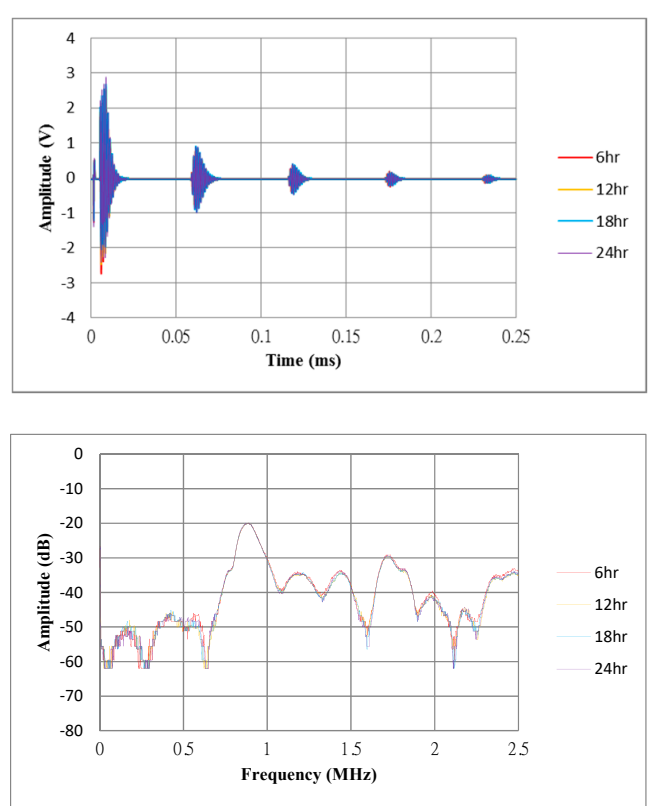

(b)

Figure 18. (a) Time and frequency responses of the CMUTs with gold electrodes; (b) Time and frequency responses of the CMUTs with silver nanowire electrodes.

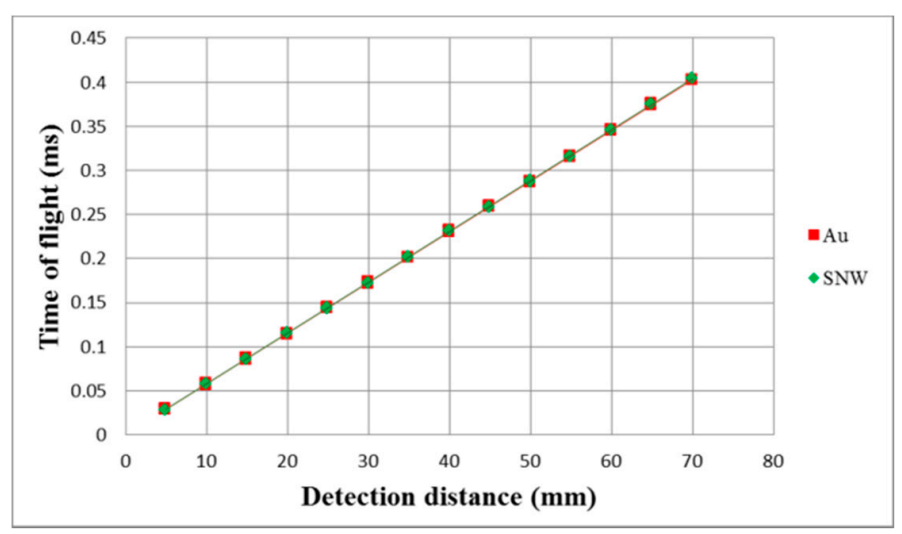

Figure 19. Detection distance relative to time of flight.

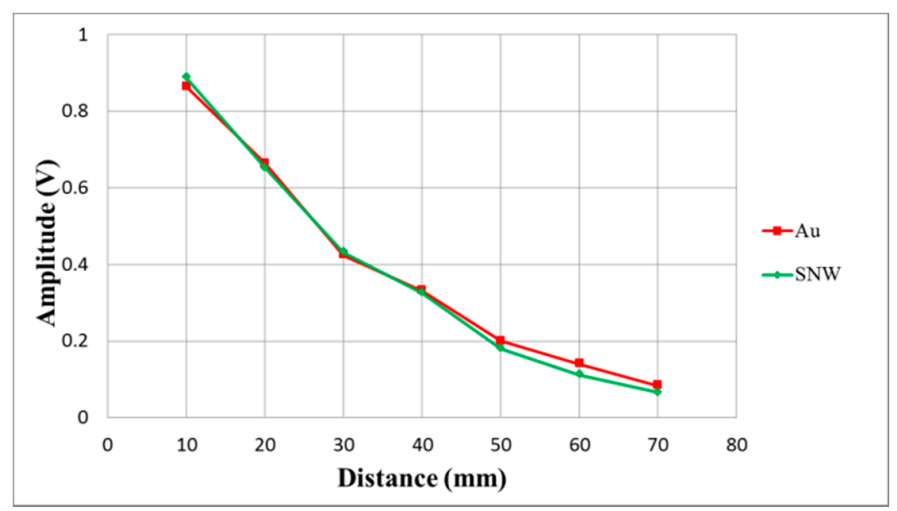

Figure 20. Reflection signals at different detection distances. 
The transparent flexible CMUTs were studied on both flat and curved surfaces to determine the maximum detection distances for curved displays and wearable electronics applications. The CMUTs were mounted on a cylinder with a $40 \mathrm{~mm}$ curvature radius to detect flat targets and a finger. The maximum detection distances were determined in $10 \mathrm{~mm}$ increments until the reflection signal amplitude diminished to $50 \mathrm{mV}$. Figure 21 shows a photograph of a finger being detected by the silver nanowire CMUT on a curved surface. Figure 22 presents the experimental results of the CMUT on both flat and curved surfaces to detect a flat target and a finger. Table 3 summaries the reflection signal amplitudes at a distance of $10 \mathrm{~mm}$ and the maximum detection distances under different operating conditions. The CMUT on the flat surface obtained a maximum detection distance of $70 \mathrm{~mm}$ and $50 \mathrm{~mm}$ from the flat target and finger, respectively. The CMUT on the curved surface obtained a maximum detection distance of $50 \mathrm{~mm}$ and $40 \mathrm{~mm}$ from the flat object and finger.

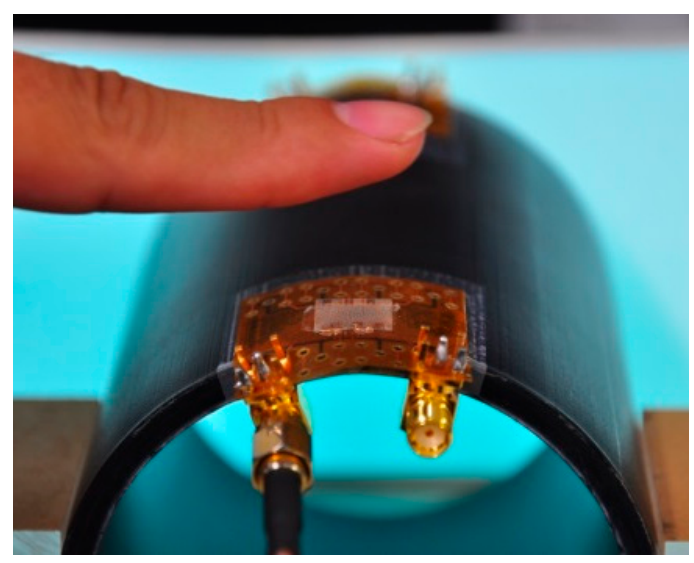

Figure 21. A transparent CMUT mounted on a $40 \mathrm{~mm}$ curvature radius surface to detect a finger.

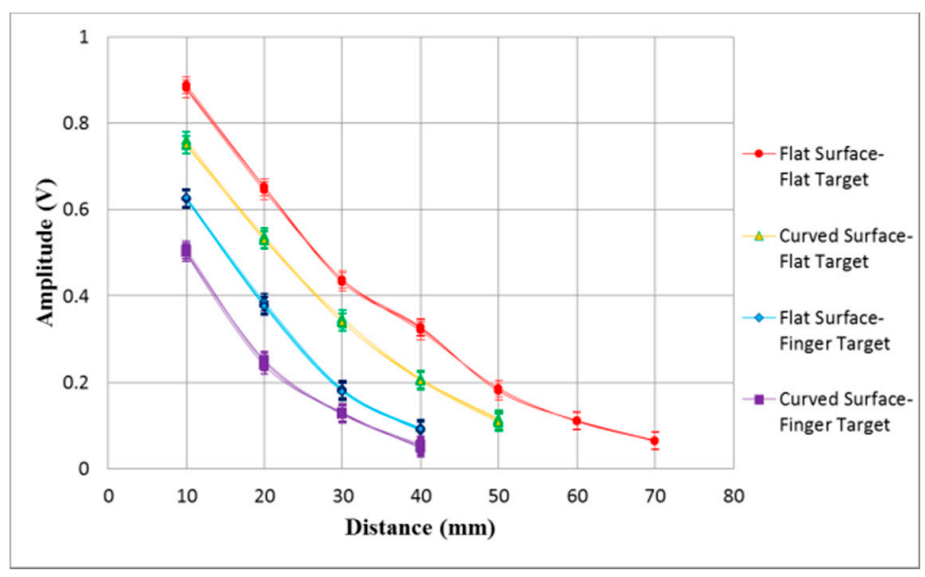

Figure 22. Distance measurement signal of the transparent CMUTs mounted on flat and curved surfaces to detect a flat target and a finger.

Table 3. Reflection signals and maximum detection distances of transparent CMUT obtained on flat and curved surfaces for flat target and finger.

\begin{tabular}{cccc}
\hline $\begin{array}{c}\text { Mounted } \\
\text { Surface }\end{array}$ & Target Object & $\begin{array}{c}\text { Reflection Signal at } \\
\mathbf{1 0} \mathbf{~ m \mathbf { m }} \mathbf{( \mathbf { m V } )}\end{array}$ & $\begin{array}{c}\text { Maximum Detection } \\
\text { Distance (mm) }\end{array}$ \\
\hline Flat & Flat & 888 & 70 \\
Flat & Finger & 624 & 50 \\
Curved & Flat & 762 & 50 \\
Curved & Finger & 506 & 40 \\
\hline
\end{tabular}




\section{Conclusions}

This paper presents a novel transparent flexible CMUT made by low temperature roll-lamination fabrication processes. Three transparent electrode materials, ITO, AZO, and silver nanowire, were applied for the CMUT top electrodes. This research found that ultrasonic vibration caused cracks of the ITO and AZO transparent electrodes on the vibrating membrane. The CMUT adopted silver nanowire transparent electrodes that can continuously operate over $24 \mathrm{~h}$ without any performance deterioration. The CMUT on the flat surfaces can detect a flat target at distances up to $70 \mathrm{~mm}$ with a linearity error of $0.141 \mathrm{~mm}$. The transducer, when operated on a curved surface with a $40 \mathrm{~mm}$ curvature radius, detected a finger at a distance of $40 \mathrm{~mm}$. The research compared the performances of two CMUTs using a gold non-transparent electrode and a silver nanowire transparent electrode. Except for transmittance there is no significant difference between the two CMUTs in terms of sensor characteristics and operating conditions. The transparent flexible CMUT can be easily integrated with a curved display and wearable electronics for non-contacting control at short distances and provides more advanced human-machine interaction than existing touch panels.

Acknowledgments: The authors would like to thank the long-term support of the MEMS and Precision Machinery Research and Development Center at National Kaohsiung University of Applied Sciences for the development of the CMUTs. In addition we would also like to acknowledge the Ministry of Sciences and Technology (MOST), R.O.C. for partial financial support under project number MOST 104-2221-E-151-012.

Author Contributions: Da-Chen Pang conceived and designed the transparent flexible capacitive micromachined ultrasonic transducer; Cheng-Min Chang fabricated and performed the experiments; Da-Chen Pang and Cheng-Min Chang analyzed the data; Da-Chen Pang and Cheng-Min Chang wrote the paper.

Conflicts of Interest: The authors declare no conflict of interest.

\section{References}

1. Hohm, D.; Hess, G. A subminiature condenser microphone with silicon-nitride membrane and silicon backplate. J. Acoust. Soc. Am. 1989, 85, 476-480. [CrossRef]

2. Suzuki, K.; Higuchi, K.; Tanigawa, H. A silicon electrostatic ultrasonic transducer. IEEE Trans. Ultrason. Ferroelectr. Freq. Control 1989, 36, 620-627. [CrossRef] [PubMed]

3. Rafiq, M.; Wykes, C. The performance of capacitive ultrasonic transducers using v-grooved backplates. Meas. Sci. Technol. 1991, 2, 168-174. [CrossRef]

4. Haller, M.I.; Khuri-Yakub, B.T. A surface micromachined electrostatic ultrasonic air transducer. IEEE Trans. Ultrason. Ferroelectr. Freq. Control 1996, 43, 1-6. [CrossRef]

5. Jin, X.; Ladabaum, I.; Khuri-Yakub, B.T. The Microfabrication of Capacitive Ultrasonic Transducers. J. Microelectromech. Syst. 1998, 7, 295-302.

6. Ladabaum, I.; Khuri-Yakub, B.T.; Spoliansky, D.; Haller, M.I. Micromachined ultrasonic transducers (MUTs). In Proceedings of the 1995 IEEE Ultrasonics Symposium, Seattle, WA, USA, 7-10 November 1995; pp. 501-504.

7. Jin, X.; Ladabaum, I.; Degertekin, F.; Calmes, S.; Khuri-Yakub, B.T. Fabrication and characterization of surface micromachined capacitive ultrasonic immersion transducers. J. Microelectromech. Syst. 1999, 8, 100-114.

8. Calmes, S.; Cheng, C.; Degertekin, F.L.; Jin, X.C.; Ergun, A.S.; Khuri-Yakub, B.T. Highly integrated 2-D capacitive micromachined ultrasonic transducers. In Proceedings of the 1999 IEEE Ultrasonics Symposium, Caesars Tahoe, NV, USA, 17-20 October 1999; pp. 1163-1166.

9. Oralkan, Ö.; Ergun, A.S.; Cheng, C.H.; Johnson, J.A.; Karaman, M.; Lee, T.H.; Khuri-Yakub, B.T. Volumetric ultrasound imaging using 2-D cMUT arrays. IEEE Trans. Ultrason. Ferroelectr. Freq. Control 2003, 50, 1581-1594. [CrossRef] [PubMed]

10. Huang, Y.; Ergun, A.S.; Hægstr"om, E.; Badi, M.H.; Khuri-Yakub, B.T. Fabricating capacitive micromachined ultrasonic transducers with wafer-bonding technology. J. Microelectromech. Syst. 2003, 12, 128-137. [CrossRef]

11. Ergun, A.S.; Huang, Y.; Zhuang, X.; Oralkan, Ö.; Yarahoglu, G.G.; Khuri-Yakub, B.T. Capacitive micromachined ultrasonic transducers: Fabrication technology. IEEE Trans. Ultrason. Ferroelectr. Freq. Control 2005, 52, 2242-2258. [PubMed] 
12. Logan, A.S.; Yeow, J.T. 1-D CMUT arrays fabricated using a novel wafer bonding process. In Proceedings of the IEEE Ultrasonics Symposium (IUS 2008), Beijing, China, 2-5 November 2008; pp. 1226-1229.

13. Zhuang, X.; Wygant, I.O.; Lin, D.S.; Kupnik, M.; Oralkan, Ö.; Khuri-Yakub, B.T. Wafer-bonded 2-D CMUT arrays incorporating through-wafer trench-isolated interconnects with a supporting frame. IEEE Trans. Ultrason. Ferroelectr. Freq. Control 2009, 56, 182-192. [CrossRef] [PubMed]

14. Olcum, S.; Oğuz, K.; Yamaner, F.Y.; Bozkurt, A.; Atalar, A.; Köymen, H. Wafer bonded capacitive micromachined underwater transducers. In Proceedings of the 2009 IEEE International Ultrasonics Symposium (IUS), Rome, Italy, 20-23 September 2009; pp. 976-979.

15. Park, K.K.; Lee, H.; Kupnik, M.; Khuri-Yakub, B.T. Fabrication of capacitive micromachined ultrasonic transducers via local oxidation and direct wafer bonding. J. Microelectromech. Syst. 2011, 20, 95-103. [CrossRef]

16. Logan, A.S.; Wong, L.L.; Yeow, J.T. A 1-D capacitive micromachined ultrasonic transducer imaging array fabricated with a silicon-nitride-based fusion process. IEEE/ASME Trans. Mechatron. 2011, 16, 861-865. [CrossRef]

17. Lee, B.C.; Nikoozadeh, A.; Park, K.K.; Khuri-Yakub, B.T. Non-flexural parallel piston movement across CMUT with substrate-embedded springs. In Proceedings of the 2014 IEEE International Ultrasonics Symposium, Chicago, IL, USA, 3-6 September 2014; pp. 591-594.

18. Gross, D.; Perroteau, M.; Certon, D.; Coutier, C.; Legros, M. Fabrication and characterization of wafer-bonded cMUT arrays dedicated to ultrasound-image-guided FUS. In Proceedings of the 2014 IEEE International Ultrasonics Symposium, Chicago, IL, USA, 3-6 September 2014; pp. 181-184.

19. Chen, J.; Wang, M.; Cheng, J.C.; Wang, Y.H.; Li, P.C.; Cheng, X. A photoacoustic imager with light illumination through an infrared-transparent silicon CMUT array. IEEE Transact. Ultrason. Ferroelectr. Freq. Control 2012, 59, 766-775. [CrossRef] [PubMed]

20. Chang, M.W.; Dong, T.M.; Gwo, T.J.; Mai, J.D.; Hsu, E. Polymer-based Capacitive Micromachined Ultrasonic Transducers (CMIT) for Micro Surgical Imaging Applications. In Proceedings of the 2006 1st IEEE International Conference on Nano/Micro Engineered and Molecular Systems, Zhuhai, China, 18-21 January 2006; pp. 61-65.

21. Chang, M.W.; Deng, H.C.; Pang, D.C.; Chen, M.Y. 6F-6 A Novel Method for Fabricating Sonic Paper. In Proceedings of the 2007 IEEE Ultrasonics Symposium, New York, NY, USA, 28-31 October 2007; pp. 527-530.

22. Wong, K.A.; Panda, S.; Ladabaum, I. Curved micromachined ultrasonic transducers. In Proceedings of the 2003 IEEE Symposium on Ultrasonics, Honolulu, HI, USA, 5-8 October 2003; pp. 572-576.

23. Zhuang, X.; Lin, D.S.; Oralkan, O.; Khuri-Yakub, B.T. Fabrication of flexible transducer arrays with through-wafer electrical interconnects based on trench refilling with PDMS. J. Microelectromech. Syst. 2008, 17, 446-452. [CrossRef]

24. Abgrall, P.; Charlot, S.; Fulcrand, R.; Paul, L.; Boukabache, A.; Gué, M.A. Low-stress fabrication of 3D polymer free standing structures using lamination of photosensitive films. Microsyst. Technol. 2008, 14, 1205-1214. [CrossRef]

25. Shi, X.; Cheng, C.H.; Peng, J. A novel stretchable CMUT array using liquid-metal electrodes on a PDMS substrate. In Proceedings of the 2012 7th IEEE International Conference on Nano/Micro Engineered and Molecular Systems, Kyoto, Japan, 5-8 March 2012; pp. 104-107.

26. Li, Z.; Chen, A.I.; Wong, L.L.; Na, S.; Yeow, J.T. Fabrication of polymer-based wafer-bonded capacitive micromachined ultrasonic transducers. In Proceedings of the 2015 IEEE International Ultrasonics Symposium (IUS), Taipei, Taiwan, 21-24 October 2015; pp. 1-4.

27. Bui, G.T.; Chen, Y.Z.; Pang, D.C. Polymer-Based Capacity Micromachined Ultrasonic Transducer for Surface Roughness Measurement. Key Eng. Mater. 2015, 661, 22-28. [CrossRef]

28. Leterrier, Y.; Medico, L.; Demarco, F.; Månson, J.A.; Betz, U.; Escola, M.F.; Atamny, F. Mechanical integrity of transparent conductive oxide films for flexible polymer-based displays. Thin Solid Films 2004, 460, 156-166. [CrossRef]

29. Yu, Z.; Xiang, L.; Xue, W.; Wang, H. The bending properties of flexible ITO films. In Proceedings of the 2007 Asia Optical Fiber Communication and Optoelectronics Conference, Shanghai, China, 17-19 October 2007; pp. 148-150. 
30. Alzoubi, K.; Hamasha, M.M.; Lu, S.; Sammakia, B. Bending fatigue study of sputtered ITO on flexible substrate. J. Disp. Technol. 2011, 7, 593-600. [CrossRef]

31. Li, T.C.; Han, C.F.; Chen, K.T.; Lin, J.F. Fatigue Life Study of ITO/PET Specimens in Terms of Electrical Resistance and Stress/Strain Via Cyclic Bending Tests. J. Disp. Technol. 2013, 9, 577-585. [CrossRef]

32. Ni, J.L.; Zhu, X.F.; Pei, Z.L.; Gong, J.; Sun, C.; Zhang, G.P. Comparative investigation of fracture behaviour of aluminium-doped ZnO films on a flexible substrate. J. Phys. D Appl. Phys. 2009, 42, 175404. [CrossRef]

33. Peng, C.Y.; Sudarsanam, H.; Hamasha, M.M.; Lu, S.; Dhakal, T.P.; Westgate, C.R. Performance of aluminum-doped zinc oxide thin films under bending fatigue conditions. In Proceedings of the 2012 IEEE Long Island Systems, Applications and Technology Conference (LISAT), Farmingdale, NY, USA, 4 May 2012; pp. 1-6.

34. Peng, C.Y.; Hamasha, M.M.; VanHart, D.; Lu, S.; Westgate, C.R. Electrical and optical degradation studies on AZO thin films under cyclic bending conditions. IEEE Trans. Device Mater. Reliab. 2013, 13, $236-244$. [CrossRef]

35. De, S.; Higgins, T.M.; Lyons, P.E.; Doherty, E.M.; Nirmalraj, P.N.; Blau, W.J.; Coleman, J.N. Silver nanowire networks as flexible, transparent, conducting films: Extremely high DC to optical conductivity ratios. ACS Nano 2009, 3, 1767-1774. [CrossRef] [PubMed]

36. Wouters, K.; Puers, R. Diffusing and swelling in SU-8: Insight in material properties and processing. J. Micromech. Microeng. 2010, 20, 095013. [CrossRef]

(C) 2017 by the authors. Licensee MDPI, Basel, Switzerland. This article is an open access article distributed under the terms and conditions of the Creative Commons Attribution (CC BY) license (http://creativecommons.org/licenses/by/4.0/). 